\title{
Effect of Application of Health Belief Model on Pregnant Women' Knowledge and Health Beliefs Regarding Urogenital Infections
}

\author{
Mahbouba Sobhy Abd El Aziz ${ }^{1}$, Heba Abdel-Fatah Ibrahim², \\ Wafaa Taha Ibrahim Elgzar ${ }^{3}$ \\ ${ }^{I}$ (Assist. Prof. of Community Health Nursing, Faculty of Nursing, Benha University, Egypt.) \\ ${ }^{2}$ (Lecturer of Obstetrics and Woman Health Nursing, Faculty of Nursing, Benha University, Egypt.) \\ ${ }^{3}$ (Lecturer Obstetrics and Gynecologic Nursing , Faculty of Nursing, Damanhour University, Egypt.) \\ Email: ${ }^{2}$ heba.abdelfattah@fnur.bu.edu.eg
}

\begin{abstract}
:
Background: Pregnancy and Urogenital Infections (UGIs) often go hand in hand so pregnant women are vulnerable group who need special preventive practice. The aim of this study was to evaluate the effect of application of Health Belief Model (HBM) on pregnant women' knowledge and health belief regarding UGIs

Methods: Quasi-experimental design was utilized. The study was conducted at Obstetrics and Gynecology Outpatient Clinic affiliated to Benha University Hospital. A purposive sample of 100 pregnant women were included in the current study. They were divided into an intervention group (50) and control group (50). Two tools were used for data collection; first tool interviewing questionnaire to collect data about the subjects' demographic data, obstetric and gynecologic history and knowledge regarding UGIs and its prevention. Second tool the HBM, it composed of the four main HBM constructs, cues for action and health behaviors to prevent UGIs.

Results: There was highly statistically significant difference $(p<0.000)$ in pregnant women' knowledge, health beliefs and their health behaviors to prevent UGIs in the intervention group compared to the control group two months after program implementation.

Conclusion and recommendation: HBM was effective in improving pregnant women' knowledge, health beliefs and health behaviors to prevent UGIs. Increase awareness of pregnant women about UGIs through regular health educational program based on HBM.

Keywords: Behavior, Health belief model, Pregnant women, Urogenital infections.
\end{abstract}

\section{Introduction}

Pregnancy causes numerous physiological changes in the woman's body especially in the urogenital tract. These changes facilitating the colonization of all kinds of germs. Increased plasma volume during pregnancy leads to decrease urine concentration and increased bladder volume. Both progesterone and estrogens levels increase during pregnancy and these will lead to decreased ureteral and bladder tone. The combinations of all these factors lead to urinary stasis and uretero-vesical reflux. Furthermore, the reduction in the pregnant women' immunity encourage the growth of both commensal and non-commensal microorganisms. [1].

Urogenital Infections (UGIs) are extremely prevalent during pregnancy and are recognized as important causes of premature labor and morbidity among pregnant women. UGIs including reproductive tract infections and Urinary Tract Infections (UTI). These infections seem to be constantly renewed and spread for diversity of causes that can be exogenous or endogenous. Exogenous are mainly due to sexual behaviors that allow the introduction of the pathogen in the genital tract. Another exogenous cause is introduction of bacteria during instrumental maneuver. Also the proximity between the vagina, urethra and anus makes the urogenital tract at risk for contamination with the normal flora present at stool especially in absence of proper perineal hygiene. Endogenous are mainly due to the colonization of germs of all kinds to the urogenital tract during pregnancy $[2,3,4]$.

Urogenital infections and its associated complications are the cause of nearly 150 million deaths / year worldwide. The disease can be developed in $40 \%-50 \%$ of women. After anemia, UTIs are the second common problem in pregnant women, which if not controlled well, can adversely affect the health of infant and/or the pregnant women. [5,6].

Urogenital infections are important cause of many maternal and fetal complications. Maternal complications include but not limited to: bacterial vaginosis, vulvovaginal candidiasis, trichomoniasis, vulvovaginitis, pelvic inflammatory disease, post abortion endometritis, chorioamnionitis, and premature labor. Early uterine contractions may be induced by cytokines and prostaglandins, which are released by microorganisms. Prematurity is strongly associated with asymptomatic bacteriuria, gonococcal cervicitis and 
bacterial vaginosis. Another complications as abortion, anemia, hypertension, phlebitis, thrombosis and chronic pyelonephritis can occur. [7,8].

Fetal complications may result from transmission of the microorganisms to the baby during delivery. This may result in ophthalmia neonatorum, chlamydial neonatal pneumonia, gonococcal ophthalmia and chlamydial infection. The infecting organisms were found to be the commensals of perineal and vaginal regions as E. coli, Staphylococcus and Candida species, which indicate fecal contamination and low personal hygiene. Furthermore, the majority of these infections are asymptomatic. So, early screening and health education of pregnant women about the preventive measures of UGIs is strongly advocated. Antenatal care should include direct questioning and urine examination to discover asymptomatic cases $[9,10]$.

Health theories and models have been valued in the field of health promotion through behavior change. They are important in explaining health risk factors and changing behavior [11]. Health Belief Model (HBM) was one of the earliest behavior change models to explain human health decision-making and subsequent behavior. Over the next few years this theory was modified to include six constructs to help predict whether people will take action to prevent, screen for, and control illness. The HBM has been used extensively to determine the relationships between health beliefs and health behaviors $[12,13]$.

The core assumption of the HBM is based on the idea that changing the health belief is the milestone for behavior change. HBM composed of four main constructs. First, perceived susceptibility: to realize and believe that they are exposed to the risk. Second, perceived severity: to understand and belief that the disease is serious public health problem, and it can lead to serious complications. Third, perceived barriers: to identify physical, psychological or financial, barriers that can hinder healthy behaviors so that the person can overcome it to assume healthy behavior. Fourth, perceived benefits: it refers to the insight of the constructive consequences that are caused by a specific act. In addition, the model suggested that cues to action can act as behavior stimuli which may be divided to internal (previous history for the disease) or external ( mass media, health team.....ect). Furthermore, the health beliefs can play an important role in behavior change which contribute to improved health status $[14,15,16]$.

creating awareness for pregnant women about UGIs turn out to be an urgent need to prevent its complications. Expanding UGIs therapeutic and preventive services is effective strategy to overcome such problem. Antenatal screening programs in public health service laboratories can help in early detection. Health education about healthy behaviors including personal hygiene should be emphasized by the nurse to all pregnant women, specifically those of low socio-economic level and illiterate one. Nurses play a valuable role in prevent UGIs among pregnant women by changing pregnant women's believes, behaviors and providing health education about regular sexual health checks, discussing the benefits of antenatal care, providing leaflets on knowledge and practices to prevent UGIs. [17,18,19].

\subsection{Significance of the study:}

The prevalence of UTIs during pregnancy worldwide ranges from 13\%-33\% [20]. In Egypt, there is limited data about the national prevalence on UGIs. This limited data may add more significance to such hidden problem. Moreover, there is no nursing studies has been found in Egypt about using HBM based program to increase awareness about such hidden problem.

Maternal UGIs have been considerably linked with a wide range of adverse perinatal and maternal outcomes, including miscarriage, stillbirth, preterm birth, fetal growth restriction, neonatal and puerperal sepsis, neonatal encephalopathy and neonatal and maternal mortality. HBM based programs can help in UGIs prevention by modifying the pregnant women beliefs, concerning self-care, early screening and treatment [21].

The nurses facilitate and increase the self-care abilities of the pregnant women to perform self-care activities. This will help pregnant women to be familiar with the signs and symptoms of UGIs, prevent infection, facilitate early detection and treatment of future infection. As changing the belief is the milestone for behavior change, the health education based on HBM can help the nurse to enhance pregnant women' knowledge, change their health beliefs, and improve their behavior regarding UGIs.

\subsection{Aim of the study:}

This study undertaken to evaluate the effect of application of HBM on pregnant women' knowledge and health beliefs regarding UGIs through: -

- Assessing the pregnant women' knowledge, health beliefs, and health behaviors to prevent UGIs to identify their needs.

- Designing and implementing health preventive program based on HBM according to pregnant women' needs.

- Evaluating the improvement of pregnant women' knowledge, health beliefs, and health behaviors to prevent UGIs. 


\subsection{Research Hypothesis:}

Pregnant women who received health educational program based on HBM are expected to have better knowledge, health beliefs, and health behaviors to prevent UGIs compared to control group.

\section{Subjects And Methods}

2.1 Research design: A quasi-experimental design was utilized to fulfill the aim of this study.

2.2 Setting: The study was carried out at Obstetrics and Gynecology Outpatient Clinic affiliated to Benha University Hospital in Benha City.

2.3 Sample: A purposive sample of 100 pregnant women were included in the current study. The inclusion criteria were: Primipara in the $1^{\text {st }}$ or $2^{\text {nd }}$ trimester of pregnancy, free from UGIs based on free urine analysis and clinical examination (done by the physician for every pregnant woman), and accepted to participate in the research. The sample was randomly divided into an intervention (50) and control (50) group.

\subsection{Tools: Two tools were used for data collection.}

\subsubsection{First tool:}

Interviewing questionnaire was developed by the researchers in Arabic language after reviewing of related literature. It encompassed three main parts:

Part I: women' socio -demographic characteristics, as age, residence, monthly income, level of education, work and telephone number.

Part II: Obstetric and gynecologic history, which include, problems with conception, duration of pregnancy, pregnancy associated conditions, minor discomforts during pregnancy, previous history of gynecologic diseases or surgery and previous history of UGIs.

Part III: Knowledge of the studied women regarding UGIs and its prevention. This part was used before and after implementation of the HBM (pre/ posttest format). It included seven open ended questions which include signs and symptoms, causes, high risk group, complications, effect on pregnancy, treatment and prevention of UGIs.

Scoring system of knowledge: A correct answer scored "two", incomplete answer was scored "one" and the incorrect or unknown answer scored "zero". The knowledge score was calculated by adding the scores for the correct answers. The total possible score ranged from 0 to 14 and means and standard deviations were calculated. The higher scores reflect higher levels of knowledge about UGIs.

\subsubsection{Second tool:}

The HBM was adapted from [16]. Modifications were done by the researchers on Arabic language. This tool composed of two parts.

Part I: Composed of the main four HBM constructs: perceived susceptibility to UGIs (four items), perceived severity of UGIs (five items), perceived barriers of performing UGIs prevention (four items), and perceived benefits of UGIs prevention (five items).

Scoring system for Part I: The four constructs included 18 items were measured using a five point Likert scale ranging from 1 (strongly disagree) to 5 (strongly agree). Subscale mean scores were obtained by summing and averaging the items. Each subscale was calculated separately, and therefore four different scores were obtained for each subject. The possible total score range was (18-90), and a higher score indicated a more positive belief toward UGIs prevention behaviors.

Part II: Composed of the other two constructs of HBM:

- Cues for action: which include previous history, complications, and past knowledge about UGIs

- Health behaviors. Which include 12 questions regarding UGIs preventive behavior. For each behavior, the positive response scored "one", and the negative response scored "zero". The total behavior score was calculated by adding the scores for the positive one. This section was used as (pre/post) format.

\subsubsection{Tools validity and reliability:}

The tools were reviewed for completeness, relevance, and legibility by an expert panel consisting of five obstetrics and gynecologic nursing as well as community health nursing experts. The panel ascertained the face and content validity of the tools. The tools were modified according to the panel judgment on simplicity of sentences and appropriateness of content. The reliability was done by Cronbach's Alpha coefficient test which revealed that each of the two tools consisted of relatively homogenous items as showed by the moderate to high reliability of each tool. The internal consistency of knowledge was 0.86 ; the total 18 -items HBM four main construct was 0.91 , and health behavior regarding UGIs prevention was 0.70 . 


\subsection{Ethical considerations:}

Each pregnant woman in both groups was informed about the aim of the study then oral consent was obtained before data collection. Strict confidentiality was safeguarded throughout the study. The women were assured that all data was used only for research purpose. they were informed that they could withdraw from the study at any time before the completion of the study. After the study was completed, handout about UGIs was distributed to control group.

\subsection{Pilot study:}

A pilot study was carried out on $10 \%$ from the total number of sample (10) pregnant women to assess the feasibility and the applicability of the tools as well to estimate the time needed for data collection. Find out the possible obstacles that might face the researchers and interfere with data collection. Those women in the pilot study were excluded from the study sample since some modifications were done.

\subsection{Field work:}

A written official agreement was obtained from the Faculty of nursing dean, then directed to Benha University Hospital Director. Written official letter was taken and delivered to the Director of Obstetrics and Gynecology Outpatient Clinic, in order to obtain their approval to conduct the study after explaining its purpose. The study was carried out through four phases: assessment, planning, implementation, and evaluation. These phases were carried out from beginning of November 2015 to the end of April 2016, covering along a period of six months. The previous mentioned setting was visited by the researchers two days/week (Sunday and Wednesday) from 9.00 am to $1.00 \mathrm{pm}$.

\subsubsection{Assessment phase:}

Upon securing official approval to conduct the study, the researchers approached and interviewed each woman individually in both control and intervention groups, explained the aim and procedures of the study, and asked for participation. Upon consent to participate, the woman was interviewed to assess demographic characteristics and knowledge regarding UGIs, HBM, and health behaviors to prevent UGIs. The data obtained during this phase constituted the baseline for further comparisons to assess the effect of the program. To avoid cross contamination of data between both groups, control group was assessed first. Average time for the completion of each woman interview was around (10-15 minutes). A number of interviewed women / week ranged from 3-5 women.

\subsubsection{Planning and implementation phase:}

Based on the needs identified in the assessment phase from the intervention group, and in view of the related literature, the researchers developed power point presentation about UGIs based on HBM with simple Arabic language to suit women' level of understanding. It stressed the areas of major deficiency in women' knowledge about UGIs. It include meaning of UGIs, causes, risk factors, signs and symptoms, diagnosis, methods of treatment, prevention, benefits of prevention and early treatment. Special attention was given to UGIs with pregnancy. The health educational program involved three sessions were conducted to a small group (3-5) of the intervention group. The program was implemented according to pregnant women' physical and mental readiness. The duration of each session lasted from thirty to forty five minutes including periods of discussion according to their achievement, progress and feedback. Different methods of teaching were used such as lecture, group discussion and brainstorming.

\subsubsection{Evaluation phase:}

After education based HBM; the effect of the program was evaluated by using the same format of pretest. Post-test was conducted for control group first then intervention group; this was done after two months of program implementation.

\subsection{Statistical analysis:}

Statistical analysis were performed using personal computer software, the Statistical Package for Social Sciences (SPSS version 20.0) was used for that purpose. Descriptive statistics were applied (e.g., mean, standard deviation, frequency and percentages). Test of significance (chi-square, Monte Carlo test, independent $t$ test and paired $t$ test) were used to test the significant differences between the groups. Pearson correlation coefficients were used. A statistically significant difference was considered at $p$-value $p \leq 0.05$, and a highly statistically significant difference was considered at $p$-value $p \leq 0.01$. 


\section{Results}

Table (1) Represents socio demographic characteristics of the study sample. It was clear that $76 \%$ and $64 \%$ of both intervention and control groups respectively aged 20 to $<30$ years. The mean age was $21.54 \pm 1.98$ and $21.90 \pm 2.05$ years for intervention and control groups respectively. $66 \%$ of the intervention group and $70 \%$ of control group were rural areas residence. Furthermore, $54 \%$ and $58 \%$ of both groups respectively had secondary education. In addition, $68 \%$ of intervention group and $58 \%$ of control group had sufficient monthly income. Finally, $72 \%$ of the intervention group and $74 \%$ of the control group were house wives. There was no statistically significant difference between intervention and control groups regarding their socio demographic characteristics.

Table (2) Displays that, $58 \%$ of intervention group and $48 \%$ of control group were in the second trimester of their pregnancy. Furthermore, $82 \%$ of intervention group as well as $66 \%$ of control group are free from conception problems. $98 \%$ and $94 \%$ of both intervention and control groups respectively complaining from minor discomfort during pregnancy. Moreover, $62 \%$ of intervention group and $80 \%$ of control group had previous history of gynecological disorders. There was no statistically significant difference between the two groups in their obstetrics and gynecologic history.

Fig. (1) Illustrates that, $60 \%$ of intervention group and $72 \%$ of control group had previous history of UGIs.

Fig. (2) Portrays that, $82 \%$ of intervention group as well $74 \%$ of control group haven't any pregnancy associated medical disorders during the current pregnancy.

Table (3) demonstrates that, there was no statistically significant difference between both intervention and control groups mean knowledge score before program implementation. Meanwhile, there was a highly statistically significant difference ( $p$-values < 0.001$)$ was observed between the two groups two months after program implementation. Also there was a highly statistically significant difference(p-values $<0.001)$ was observed within the intervention group knowledge before and two months after program implementation.

Table (4) shows that, there was no statistical significant difference was observed between the intervention and control group in the four main HBM constructs (perceived susceptibility, perceived severity, perceived barriers and perceived benefits) before program implementation. However, two months after program implementation, there was a highly statistically significant difference ( $p$-values $<0.001$ ) was observed in the four main HBM constructs. Also a general improvement in the four main HBM constructs was observed within the intervention group two months after program implementation as compared to before it.

Table (5) illustrates that, there was no statistically significant difference between both intervention and control groups before program implementation regarding health behavior to prevent UGIs. Meanwhile, there was a highly statistically significant difference (p-values $<0.001)$ two months after program implementation was observed between the two groups. Also there was a highly statistically significant difference $(p<0.001)$ before and after program implementation within the intervention group regarding their health behavior to prevent UGIs.

Fig. (3) Portrays that, $44 \%$ and $42 \%$ of intervention and control group respectively obtained their information about UGIs from health team.

Table (6) clarifies that, there was a positive highly statistically significant correlation between total knowledge and total HBM four main constructs in both intervention and control groups before and two months after program implementation. Moreover, there was a positive highly statistically significant correlation between total knowledge and health behavior scores in intervention group before and two months after program implementation.

Table (7) Illustrates that, there was a positive highly statistically significant correlation between total health behavior score and total HBM four main constructs in both intervention and control groups before and two months after program implementation.

Table (1) Distribution of the study subjects according to their socio demographic characteristics.

\begin{tabular}{|c|c|c|c|c|c|c|}
\hline \multirow[t]{2}{*}{ socio-demographic characteristics } & \multicolumn{2}{|c|}{$\begin{array}{l}\text { Intervention } \\
\text { group } \\
\mathbf{n = 5 0}\end{array}$} & \multicolumn{2}{|c|}{$\begin{array}{l}\text { Control group } \\
n=50\end{array}$} & \multirow[t]{2}{*}{$\mathrm{X}^{2}$} & \multirow[t]{2}{*}{ p value } \\
\hline & No & $\%$ & No & $\%$ & & \\
\hline $\begin{array}{l}\text { Age } \\
\text { - Less than } 20 \text { years } \\
\text { - } \quad \text { From } 20 \text { to less than } 30 \text { years } \\
\text { Age (years) Mean } \pm \text { SD }\end{array}$ & $\begin{array}{l}12 \\
38 \\
\mathbf{2 1 . 5}\end{array}$ & $\begin{array}{l}24 \% \\
76 \% \\
\text {.98 years }\end{array}$ & $\begin{array}{l}18 \\
32 \\
\mathbf{2 1 . 9}\end{array}$ & $\begin{array}{l}36 \% \\
64 \% \\
\text { years }\end{array}$ & 1.714 & 0.190 \\
\hline \begin{tabular}{lc}
\multicolumn{2}{l}{ Residence } \\
- & Urban \\
- & Rural
\end{tabular} & $\begin{array}{l}17 \\
33\end{array}$ & $\begin{array}{l}34 \% \\
66 \%\end{array}$ & $\begin{array}{l}15 \\
35\end{array}$ & $\begin{array}{l}30 \% \\
70 \%\end{array}$ & 0.184 & 0.415 \\
\hline $\begin{array}{l}\text { Level of education } \\
\text { - } \quad \text { Read and write } \\
\text { - } \quad \text { Secondary education }\end{array}$ & $\begin{array}{l}9 \\
27\end{array}$ & $\begin{array}{l}18 \% \\
54 \%\end{array}$ & $\begin{array}{l}8 \\
29\end{array}$ & $\begin{array}{l}16 \% \\
58 \%\end{array}$ & 0.783 & 0.854 \\
\hline
\end{tabular}


Effect of Application of Health Belief Model on Pregnant Women' Knowledge and Health...

\begin{tabular}{|c|c|c|c|c|c|c|}
\hline - University education & 14 & $28 \%$ & 13 & $26 \%$ & & \\
\hline \begin{tabular}{ll}
\multicolumn{2}{l}{ Monthly income } \\
- & Sufficient \\
- & Insufficient
\end{tabular} & $\begin{array}{l}34 \\
16\end{array}$ & $\begin{array}{l}68 \% \\
32 \%\end{array}$ & $\begin{array}{l}29 \\
21\end{array}$ & $\begin{array}{l}58 \% \\
42 \%\end{array}$ & 1.073 & 0.204 \\
\hline $\begin{array}{l}\text { Work } \\
\text { - } \quad \text { House wife } \\
\text { - } \quad \text { Employee }\end{array}$ & $\begin{array}{l}36 \\
14\end{array}$ & $\begin{array}{l}72 \% \\
28 \%\end{array}$ & $\begin{array}{l}37 \\
13\end{array}$ & $\begin{array}{l}74 \% \\
26 \%\end{array}$ & 0.051 & 0.500 \\
\hline
\end{tabular}

Table (2) Distribution of the study subjects according to their obstetric and gynecologic history.

\begin{tabular}{|c|c|c|c|c|c|c|}
\hline Groups & & & & & $\begin{array}{l}\text { Test of } \\
\text { significance }\end{array}$ & p value \\
\hline Obstetrics and gynecologic history & No & $\%$ & No & $\%$ & & \\
\hline $\begin{array}{ll}\text { Trimester of pregnancy } \\
-\quad & \text { First trimester } \\
- & \text { Second trimester }\end{array}$ & $\begin{array}{l}21 \\
29\end{array}$ & $\begin{array}{l}42 \% \\
58 \%\end{array}$ & $\begin{array}{l}26 \\
24\end{array}$ & $\begin{array}{l}52 \% \\
48 \%\end{array}$ & $\begin{array}{c}X^{2} \\
1.004\end{array}$ & 0.316 \\
\hline $\begin{array}{ll}\text { Problems in conception } \\
- & \text { Free from problem in conception } \\
- & \text { Delayed pregnancy } \\
- & \text { High prolactin level } \\
- & \text { Polycystic ovary } \\
\end{array}$ & $\begin{array}{l}41 \\
5 \\
3 \\
1 \\
\end{array}$ & $\begin{array}{l}82 \% \\
10 \% \\
6 \% \\
2 \%\end{array}$ & $\begin{array}{l}33 \\
10 \\
5 \\
2 \\
\end{array}$ & $\begin{array}{l}66 \% \\
20 \% \\
10 \% \\
4 \%\end{array}$ & ${ }^{\mathrm{MC}} 0.348$ & 0.339 \\
\hline $\begin{array}{l}\text { Minor discomfort of pregnancy } \\
-\quad \text { Having minor discomfort during pregnancy } \\
-\quad \text { Not having minor discomfort during pregnancy }\end{array}$ & $\begin{array}{l}49 \\
1 \\
\end{array}$ & $\begin{array}{l}98 \% \\
2 \%\end{array}$ & $\begin{array}{l}47 \\
3 \\
\end{array}$ & $\begin{array}{l}94 \% \\
6 \%\end{array}$ & ${ }^{\mathrm{MC}} 0.620$ & 0.610 \\
\hline $\begin{array}{l}\text { Previous gynecological disorder } \\
-\quad \text { Having Previous gynecological disorder } \\
-\quad \text { Not having Previous gynecological disorder }\end{array}$ & $\begin{array}{l}37 \\
13\end{array}$ & $\begin{array}{l}74 \% \\
26 \%\end{array}$ & $\begin{array}{l}40 \\
10\end{array}$ & $\begin{array}{l}80 \% \\
20 \%\end{array}$ & $\begin{array}{c}\mathrm{X}^{2} \\
0.508\end{array}$ & 0.476 \\
\hline
\end{tabular}

${ }^{\mathrm{MC}}$ : Monte Carlo test $\mathbf{X}^{2}$ : Chi-Square test

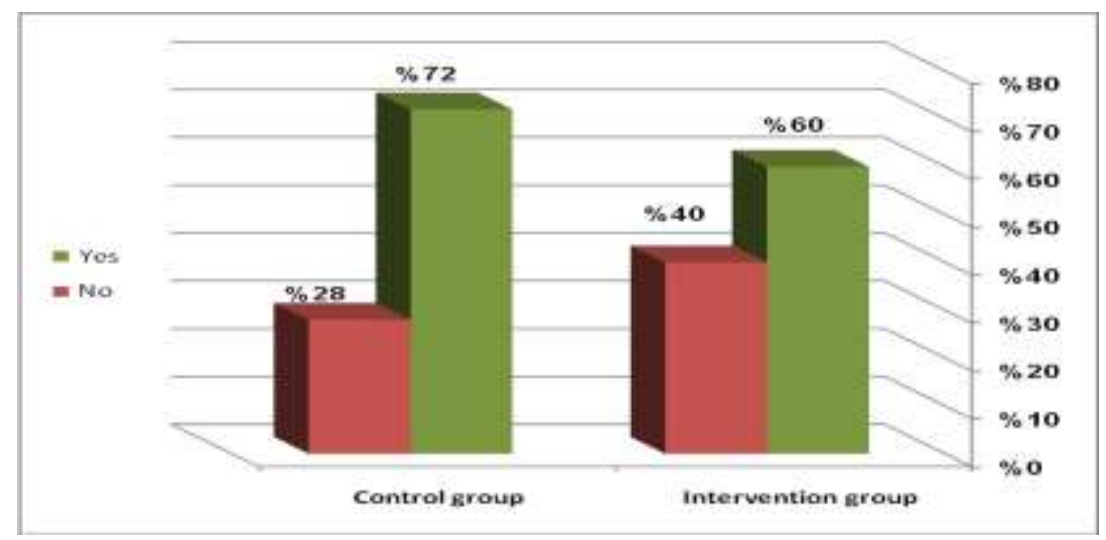

Fig. (1) Distribution of the study subjects according to their previous history of UGIs $(n=100)$.

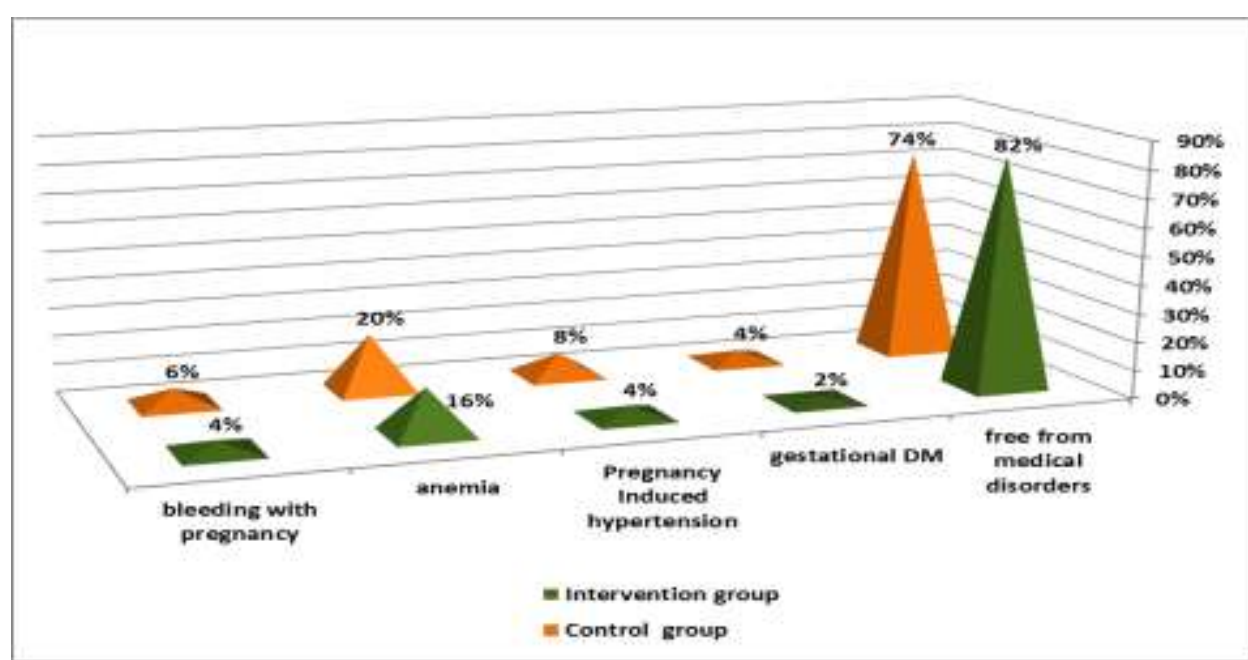

Fig. (2) Distribution of the study subjects according to the their medical history during the current pregnancy. $(n=100)$. 
Table (3) Mean differences between intervention and control group knowledge before and two months after program implementation. $(\mathrm{n}=100)$

\begin{tabular}{|c|c|c|c|c|c|c|}
\hline \multicolumn{7}{|c|}{ Total knowledge score } \\
\hline Groups & \multirow{2}{*}{\multicolumn{2}{|c|}{$\begin{array}{c}\begin{array}{c}\text { Intervention group } \\
\mathbf{n}=\mathbf{5 0}\end{array} \\
\text { Mean } \pm \text { SD }\end{array}$}} & \multicolumn{2}{|c|}{$\begin{array}{c}\text { Control group } \\
n=50\end{array}$} & \multicolumn{2}{|c|}{$\begin{array}{l}\text { Significance between } \\
\text { groups }\end{array}$} \\
\hline Maximum score $=(14)$ & & & \multirow{3}{*}{\multicolumn{2}{|c|}{$\begin{array}{l}\text { Mean } \pm \text { SD } \\
4.12 \pm 2.82 \\
4.38 \pm 2.84\end{array}$}} & $\left(t_{1}\right)$ & P value \\
\hline Before program implementation & \multirow{2}{*}{\multicolumn{2}{|c|}{$\begin{array}{l}4.40 \pm 2.68 \\
11.46 \pm 2.06\end{array}$}} & & & 0.507 & 0.613 \\
\hline 2 months after program implementation & & & & & 14.245 & $0.000 * *$ \\
\hline \multirow{2}{*}{$\begin{array}{l}\text { Significance within group ( before and } \\
\text { after program implementation) }\end{array}$} & $\left(\mathbf{t}_{2}\right)$ & P Value & $\left(t_{2}\right)$ & P Value & & \\
\hline & 20.598 & $0.000 * *$ & 0.957 & 0.343 & & \\
\hline
\end{tabular}

$$
\left(\mathbf{t}_{\mathbf{1}}\right) \text { Independent } \mathrm{t} \text { test }\left(\mathbf{t}_{\mathbf{2}}\right) \text { Paired } \mathrm{t} \text { test. }
$$

**A highly statistical significant difference $(\mathrm{p} \leq 0.001)$

Table (4) Mean differences between intervention and control group regarding HBM main four constructs before and two months after program implementation $(\mathrm{n}=100)$

\begin{tabular}{|c|c|c|c|c|c|c|c|c|}
\hline \multirow{3}{*}{$\begin{array}{l}\text { HBM main four } \\
\text { constructs (maximum } \\
\text { score) }\end{array}$} & \multicolumn{4}{|c|}{ Before implementation } & \multicolumn{4}{|c|}{2 months after implementation } \\
\hline & \multirow{2}{*}{$\begin{array}{c}\text { Intervention } \\
\text { group } \mathbf{n}=\mathbf{5 0} \\
\text { Mean } \pm \text { SD } \\
\end{array}$} & \multirow[t]{2}{*}{$\begin{array}{c}\begin{array}{c}\text { Control group } \\
\mathbf{n}=50\end{array} \\
\text { Mean } \pm \text { SD }\end{array}$} & \multicolumn{2}{|c|}{$\begin{array}{l}\text { Significance } \\
\text { between } \\
\text { intervention } \\
\text { and control } \\
\text { group }\end{array}$} & \multirow[t]{2}{*}{$\begin{array}{l}\text { Intervention } \\
\text { group } \mathbf{n}=\mathbf{5 0} \\
\text { Mean } \pm \text { SD } \\
\end{array}$} & \multirow[t]{2}{*}{$\begin{array}{c}\text { Control } \\
\text { group } n=50 \\
\text { Mean } \pm \text { SD } \\
\end{array}$} & \multicolumn{2}{|c|}{$\begin{array}{l}\text { Significance } \\
\text { between } \\
\text { intervention } \\
\text { and control } \\
\text { group }\end{array}$} \\
\hline & & & $\left(\mathbf{t}_{1}\right)$ & P value & & & $\left(\mathbf{t}_{\mathbf{1}}\right)$ & Pvalue \\
\hline $\begin{array}{l}\text { - Perceived susceptibility } \\
\text { (20) }\end{array}$ & $12.78 \pm 2.97$ & $12.20 \pm 3.40$ & 1.220 & 0.225 & $17.12 \pm 1.88$ & $12.22 \pm 3.40$ & 8.917 & $0.000 * *$ \\
\hline $\begin{array}{l}\text { Significance within } \\
\text { group }\end{array}$ & \multicolumn{8}{|c|}{$\begin{array}{l}\text { Intervention group: }\left(t_{2}\right)=10.484(p=0.000 * *) \\
\text { Control group: }\left(t_{2}\right)=0.275(P=0.785)\end{array}$} \\
\hline - Perceived severity (25) & $15.46 \pm 3.08$ & $16.22 \pm 3.11$ & 1.226 & 0.223 & $22.22 \pm 1.92$ & $16.18 \pm 3.14$ & 11.602 & $\mathbf{0 . 0 0 0} * *$ \\
\hline $\begin{array}{l}\text { Significance within } \\
\text { group }\end{array}$ & \multicolumn{8}{|c|}{$\begin{array}{l}\text { Intervention group: }\left(t_{2}\right)=13.361(p=0.000 * *) \\
\text { Control group: }\left(t_{2}\right)=0.157(P=0.876)\end{array}$} \\
\hline - Perceived barriers(20) & $12.70 \pm 2.65$ & $12.38 \pm 3.54$ & 0.511 & 0.610 & $16.84 \pm 1.95$ & $12.60 \pm 3.52$ & 7.445 & $\mathbf{0 . 0 0 0} * *$ \\
\hline $\begin{array}{l}\text { Significance within } \\
\text { group }\end{array}$ & \multicolumn{8}{|c|}{$\begin{array}{l}\text { Intervention group: }\left(t_{2}\right)=9.928(p=0.000 * *) \\
\text { Control group: }\left(t_{2}\right)=1.448(P=0.154)\end{array}$} \\
\hline - Perceived benefits (25) & $17.36 \pm 2.88$ & $17.78 \pm 2.96$ & 0.718 & 0.474 & $22.98 \pm 1.34$ & $17.72 \pm 2.99$ & $\mathbf{1 1 . 3 4 1}$ & 0.000 $* *$ \\
\hline $\begin{array}{l}\text { Significance within } \\
\text { group }\end{array}$ & \multicolumn{8}{|c|}{$\begin{array}{l}\text { Intervention group: }\left(t_{2}\right)=12.726(p=0.000 * *) \\
\text { Control group: }\left(t_{2}\right)=0.326(P=0.746)\end{array}$} \\
\hline - Total score $=90$ & $58.72 \pm 9.82$ & $56.86 \pm 12.34$ & 0.834 & 0.407 & $78.38 \pm 5.71$ & $56.98 \pm 12.37$ & 11.102 & $\mathbf{0 . 0 0 0} * *$ \\
\hline $\begin{array}{l}\text { Significance within } \\
\text { group }\end{array}$ & \multicolumn{8}{|c|}{$\begin{array}{l}\text { Intervention group: }\left(t_{2}\right)=121.600(P=0.000 * *) \\
\text { Control group: }\left(t_{2}\right)=0.207(p=0.837)\end{array}$} \\
\hline
\end{tabular}

$\left(\mathbf{t}_{1}\right)$ Independent $\mathrm{t}$ test $\quad\left(\mathbf{t}_{2}\right)$ Paired $\mathrm{t}$ test.
$* *$ A highly statistical significant difference $(\mathrm{p} \leq 0.001)$

Table (5) Mean differences between intervention and control group regarding to their health behavior to prevent UGIs before and two months after program implementation. $(n=100)$

\begin{tabular}{|c|c|c|c|c|}
\hline \multicolumn{5}{|c|}{ Health behavior total score } \\
\hline Groups & $\begin{array}{l}\text { Intervention } \\
\text { group } \mathbf{N}=\mathbf{5 0}\end{array}$ & $\begin{array}{c}\text { Control } \\
\text { group } \mathrm{N}=\mathbf{5 0}\end{array}$ & \multicolumn{2}{|c|}{$\begin{array}{c}\text { Significance between } \\
\text { groups }\end{array}$} \\
\hline Maximum score $=(\mathbf{1 2})$ & Mean \pm SD & Mean \pm SD & $\left(t_{1}\right)$ & P value \\
\hline $\begin{array}{ll}- & \text { Before implementation } \\
- & 2 \text { months after implementation }\end{array}$ & $\begin{array}{l}6.58 \pm 1.83 \\
11.62 \pm 0.60\end{array}$ & $\begin{array}{l}6.20 \pm 2.57 \\
6.22 \pm 2.44\end{array}$ & $\begin{array}{l}0.851 \\
15.172\end{array}$ & $\begin{array}{l}\mathbf{0 . 3 9 7} \\
\mathbf{0 . 0 0 0} * *\end{array}$ \\
\hline Significance within group(p value) & $\begin{array}{l}\text { Intervention g } \\
\text { Control group }\end{array}$ & $\begin{array}{l}\text { up: }\left(t_{2}\right)=19.48 \\
\left.t_{2}\right)=1.093(p=\end{array}$ & $\begin{array}{l}p=0.00( \\
280)\end{array}$ & \\
\hline
\end{tabular}

$\left(\mathbf{t}_{1}\right)$ Independent $\mathrm{t}$ test

$\left(\mathbf{t}_{2}\right)$ Paired t test.

$* *$ A highly statistical significant difference $(\mathrm{p} \leq 0.001)$

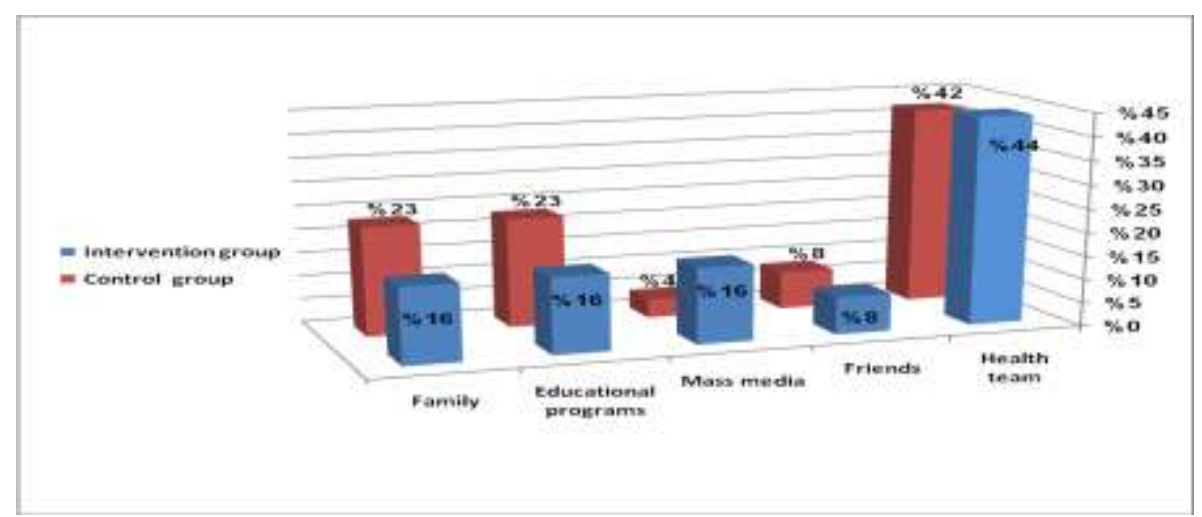

Fig. (3) Distribution of the study subjects according to their sources of information about UGIs ( $\mathrm{n}=100$ ). 
Table (6) Correlation coefficient between the total knowledge, total HBM four main constructs and health behavior regarding UGIs prevention of the study subjects before and two months after program implementation $(\mathrm{n}=100)$.

\begin{tabular}{|c|c|c|c|c|c|}
\hline \multirow{3}{*}{\multicolumn{2}{|c|}{ Variables }} & \multicolumn{4}{|c|}{ Total knowledge } \\
\hline & & \multicolumn{2}{|c|}{$\begin{array}{c}\text { Intervention group } \\
\mathbf{n}=\mathbf{5 0}\end{array}$} & \multicolumn{2}{|c|}{$\begin{array}{c}\text { Control group } \\
\mathbf{n}=\mathbf{5 0}\end{array}$} \\
\hline & & $\mathbf{r}$ & $\mathbf{P}$ & $\mathbf{r}$ & $\mathbf{P}$ \\
\hline $\begin{array}{l}\text { total } \mathrm{HBM} \text { four } \\
\text { main constructs }\end{array}$ & $\begin{array}{ll}- & \text { Before implementation } \\
- & 2 \text { months after implementation }\end{array}$ & $\begin{array}{l}0.458 \\
0.892\end{array}$ & $\begin{array}{l}0.001 * * \\
0.000 * *\end{array}$ & $\begin{array}{l}0.370 \\
0.393\end{array}$ & $\begin{array}{r}0.008 * * \\
0.005 * *\end{array}$ \\
\hline $\begin{array}{c}\text { Total health } \\
\text { behavior }\end{array}$ & $\begin{array}{ll}- & \text { Before implementation } \\
- & 2 \text { months after implementation }\end{array}$ & $\begin{array}{l}0.451 \\
0.870\end{array}$ & $\begin{array}{l}0.001 * * \\
0.000 * *\end{array}$ & $\begin{array}{l}0.333 \\
0.312\end{array}$ & $\begin{array}{l}0.018 * \\
0.027 *\end{array}$ \\
\hline
\end{tabular}

Table (7) Correlation coefficient between total HBM four main constructs and health behavior to prevent UGIs among study subjects before and two months after program implementation $(n=100)$.

\begin{tabular}{|l|l|l|l|c|c|}
\hline Variables & \multicolumn{3}{|c|}{ Total HBM four main constructs } \\
\cline { 3 - 6 } & & \multicolumn{2}{|c|}{$\begin{array}{c}\text { Intervention group } \\
\mathbf{n}=\mathbf{5 0}\end{array}$} & \multicolumn{1}{|c|}{$\begin{array}{c}\text { Control group } \\
\mathbf{n}=\mathbf{5 0}\end{array}$} \\
\cline { 3 - 6 } & $\mathbf{r}$ & 0.529 & $0.000 * *$ & $\mathbf{0 . 4 9 7}$ & $\mathbf{0 . 0 0 0} * *$ \\
\hline Total health behavior & $-\quad$ Before implementation & 0.804 & $0.000 * *$ & $\mathbf{0 . 4 0 4}$ & $\mathbf{0 . 0 0 4} * *$ \\
\hline
\end{tabular}

\section{Discussion}

Nursing is an integral part of the health care system and nurses direct their energies towards the promotion, maintenance \& restoration of health. Therefore, regular educations based on HBM seem to promote preventive behaviors related to UGIs and reduce its incidence [22].

In the present study findings, no significant differences were found among the intervention and the control groups in terms of age, educational level, residence, monthly income and work. This results mean that the two groups under study are homogenous. This is similar to Khoramabadi et al., 2016 [23] as well as Shahnazi et al., 2015 [24]. They conducted their studies to detect the impact of education intervention based on HBM on different health behavior among pregnant women. They pointed out that, there was no significant difference between the intervention and the control groups regarding their age, educational level, monthly income and occupation.

On investigating pregnant women' knowledge about urogenital infections, The present study findings revealed that, there was a highly significant improvement in the intervention group knowledge two months after program implementation compared to the control group. Also there was a highly significant improvement within the intervention group before and after program implementation.

The results of the present study agree with at least three other researches. First, Ahmed, 2015 [25]. who had studied the effect of intervention guidelines on self-care practices of pregnant women with urinary tract infection. He found that there was significant improvement of the pregnant women knowledge regarding all items in relation to urinary tract infection immediately after program implementation and 3 months later. Second and third Jalali et al., 2014 and Taghdisi \& Sadeghi, 2012 [26,27] both of them had evaluated the effect of health education based on different theories on UTI preventive behavior among pregnant women. they documented that the mean knowledge about UTI were significantly increased in the intervention group compared to control group after intervention. This improvement of knowledge post program in the present study may be attributed to the ability of the studied subjects to gain knowledge easily where more than three quarter of them had secondary or university education and they are interested to know about UGIs and its preventive measures.

Regarding The four main HBM constructs, The current study results showed a significant increase in the mean scores of perceived susceptibility on the intervention group compared to control group two months after program implementation. This result is compatible to Aligol et al., 2014 and Karimy et al., 2012 [28,29] studies. Both of them had studied the effects of education based HBM on promoting preventive behaviors regarding brucellosis among women. They documented that the mean scores of perceived susceptibility to brucellosis increased in the intervention group as compared to control group after program implementation. On the other hand Bakhtari Aqdam et al., 2012 [30] had studied the effect of HBM based education on screening behaviors of breast cancer among women. He showed no significant difference between intervention and control group in the perceived susceptibility after the education. The difference between the present study result and Bakhtari Aqdam et al study may be attributed to the natural difference between the UGIs and breast cancer risk factors. Where, the physiological changes during pregnancy precipitate the women to UGIs. Also, UGIs is more common than breast cancer among pregnant women. 
In the present study, the perceived severity score was found to be significantly higher among the intervention group compared to the control group two months after program implementation. In line with the current study findings, Farma et al., 2014 [31] who had studied the effect of education based HBM on preventive behaviors of breast cancer in female teachers of Zahedan city. He indicated that the score of the perceived severity in the intervention group was meaningfully increased, compared to the control group, after the program.

Additionally, the current findings also reported a significant increase in the mean scores of perceived barriers on the intervention group compared to control group two months after program implementation. This result is similar to at least two studies Khoramabadi et al., 2016 and Shahnazi et al., 2015[23,24]. They had studied the effects of education based HBM on different health behavior among pregnant women. They documented that a significant increase in the mean scores of perceived barriers on the intervention group compared to control after the intervention. On the contrary, Karimy et al., 2012 [32] who had studied the effect of health education program based on HBM on the performance of pap smear test among women. He reported significant decrease in the perceived barrier mean score within the intervention group before and after the intervention. The difference between the current study result and Karimy et al study may be attributed to the difference of scoring system regarding perceived barrier construct. Where in the present study the high barrier perceived scored one while the low barrier perceived scored five.

The present study findings indicated that the mean scores of perceived benefits to UGIs increased in intervention group two months after program implementation with highly statistically significant difference observed between intervention and control group. This is consistent with the previously mentioned studies Tehrani et al., 2014 and Sadeghi et al., 2012 [16,33] they found a significant improvement in intervention group post intervention in perceived benefits to UTI as compared to control group.

The current study finding indicated that, there were a highly statistically significant differences in the total health belief score regarding UGIs were observed between the intervention and control group two months after program implementation. Also general improvement in total health belief score was observed within the intervention group two months after program implementation as compared to before it. This results similar to Jahanbin et al., 2015 and Yossif \& EL Sayed, 2014 [34,35]. The former had studied the effect of peereducation on UTI-related preventive behavior based HBM among high school female students in shiraz. He found that the mean scores of HBM is significantly increased among his intervention group immediately and one month after the intervention. The latter had evaluated the effect of self-learning package based on HBM on cervical cancer prevention among female university students. She reported a highly statistically significant difference observed between intervention and control group in their total health belief score after self-learning package.

In the present study, the cues for action were either internal or external stimuli. Internal stimuli include previous history of UGIs. The external stimuli were the information about UGIs received from different sources as health team, educational program, friends, family and mass media. Health team was the most prevalent external stimuli for current study participant to practice UGIs preventive behavior. This result is in accordance with the previously mentioned Tehrani et al., 2014 study[16]. He documented that the cues to action among his participant were history of urinary tract infection and information received from media, educational booklets, books, friends, family and education. Also Karimy et al., 2012 [32] had reported that healthcare personnel constitute the most important external cues to action for performing Pap smear among their participants. Another 2012 study performed by Pirzadeh and Mazaheri [36] about the effect of education based on HBM on women practice related to Pap smear, reported that around half of their participant had chosen health staff as the performance guide for them. This result seems to be logic as usually when the persons exposed to the disease they seek help from health care team.

The current study clarified that there was a highly significant improvement in the health behavior to prevent UGIs in the intervention group compared to the control group two months after program implementation. Also, significant improvement was observed within the intervention group health behavior before and two months after program implementation. This result is in agreement with the previously mentioned studies Tehrani et al., 2014, Taghdisi \& Sadeghi, 2012 and Jahanbin et al., 2015 [16, 27, 34], they stated that education based on HBM can promote preventive behaviors of UTI and reduce the risk of the disease among pregnant women.

A very recent study done by Rahimi et al., 2016 [37] based on the HBM to predict the preventive behaviors of urinary tract infections among pregnant women, showed that education based on HBM which involves attitudes and beliefs of the participants can be useful and effective in order to promote preventive behaviors of the UTI. The present study result is also in the same line with some other recent studies Khoramabadi et al., 2016 and Shahnazi et al., 2015 [23,24] who studied the effect of education based on HBM on different health behaviors. They emphasized that changing the health belief is prerequisite for behavior change. 
It was found that, there was a positive statistically significant correlation between knowledge and health beliefs as well as between knowledge and health behavior to prevent UGIs in both intervention and control group before and two months after program implementation. These findings are in congruence with at least three previously mentioned studies Jalali et al., 2014 ; Yossif \& EL Sayed, 2014 and Rahimi et al., 2016 [26,35,37]. The first clarified that knowledge and health belief about UTI are considered to be motivating factors for behavior change. The second clarified that, there was a positive highly statistically significant correlation between total knowledge and total health beliefs scores as well as between total knowledge and total intention to practice health behavior in both intervention and control groups before and two months after selflearning package. The third showed a significant correlation between knowledge and all HBM construct with health behavior. This may be attributed to the fact that changing the belief is the milestone for behavior change. All these studies based on HBM which play on changing the belief.

Additionally, the present study results confirmed that, there was a positive highly statistically significant correlation between health beliefs and health behavior in both intervention and control groups before and two months after program implementation. This finding is consistent with the previously mentioned Yossif \& EL Sayed, 2014 study [35]. They stated that there was a statistically significant correlation between total health beliefs score and total intention score to practice health preventive behavior in both intervention and control groups before and two months after the self-learning package. Also Juntasopeepun et al., 2012 [38] who highlighted that beliefs play a vital role in a person's decision to engage in health preventive behaviors. Accordingly, designing an educational program based on the HBM is an urgent need to increase the pregnant women awareness about the severity and susceptibility of UGIs which can enhance their preventive practice.

\section{Conclusion}

Based on the results of the present study, it can be concluded that HBM is effective in improving pregnant women' knowledge, health belief and health behaviors regarding UGIs.

\section{Recommendations}

Based on results of the present study, the following recommendations can be suggested:

- Nurses should increase pregnant women awareness about UGIs through regular educational program based on HBM.

- $\quad$ Nurses should provide pregnant women with instructional booklets about UGIs based on HBM to improve their knowledge and health belief.

- Replication of this study on a large sample and in different settings is recommended for generalization of results.

\section{Acknowledgements}

The authors would like to express their appreciation to all participant who willingly participated in the study.

\section{References}

[1]. Johnson, K. and Kim, E. Urinary tract infections in pregnancy, 2015, Available at: http://emedicine.medscape.com/article/452604 overview. Updated: May 06, 2015

[2]. Adukauskiene, D., Cicinskaite, I., Vitkauskiene, A., Macas, A., Tamosi nas, R. and Kinderyte, A, Hospital- acquired urinary tract infections, Medicina (Kaunas). 42(12) 2006, 957-64.

[3]. Barka, MS., Benyoub, NH. and Zaoui, Prevalence of urogenital tract infections during pregnancy in Maghnia hospital (Algeria), International Journal of Current Microbiology and Applied Science 3(1), 2014, 1-7.

[4]. Sznajder, KK., Harlow, SD., Burgard, SA., Wang, Y., Han, C. and Liu J, Urogenital infection symptoms and occupational stress among women working in export production factories in Tianjin, China, Asian Pacific Journal of Reproduction, 3(2), 2014, 142149.

[5]. Giraldo, P., Araújo, E., Junior, J., Amaral, R., Passos, M. and Gonçalves A, The prevalence of urogenital infections in pregnant women experiencing preterm and full-term labor, Infectious Disease in Obstetrics and Gynecology. PMC3296138, 2012, available at http://www.ncbi.nlm.nih.gov/pmc/articles/PMC3296138/

[6]. Amiri, M., Lavasani, Z., Norouzirad, R., Najibpour, R., Mohamadpour, M., Nikpoor, A., Raeisi, M. and Marzouni, H. Prevalence of urinary tract infection among pregnant women and its complications in their newborns during the birth in the hospitals of Dezful city, Iran, 2012 - 2013, Iran Red Crescent Med J. 17(8), 2015, e26946.

[7]. Biggs, WS. and Williams, RM. Common gynecologic infections. Primary Care. 36(1), 2009, 33-51.

[8]. Genc, MR. and Ford, CE. The clinical use of inflammatory markers during pregnancy. Current Opinion in Obstetrics and Gynecology, 22(2), 2010, 116-121.

[9]. Faidah, HS., Ashshi AM., Abou El-Ella GA., Al-Ghamdi AK. and Mohamed AM. Urinary tract infections among pregnant women in Makkah, Saudi Arabia, Biomedical \& Pharmacology Journal, 6(1), 2013, 01-07.

[10]. Oladeinde, BH., Omoregie, R. and Oladeinde, OB. Asymptomatic urinary tract infection among pregnant women receiving antenatal care in a traditional birth home in Benin city, Nigeria Ethiopian, Journal of Health Science, 25(1), 2015, 3-8.

[11]. Corcoran, N. Communicating health: strategies for health promotion (1st ed. London: SAGE Publications Ltd; 2007$)$ p. 9.

[12]. Glanz, K., Rimer, B. and Viswanath, K. Health Behaviour and Health Education: Theory, Research and Practice (4th ed. San Francisco: Jossey-Bass; 2008) pp. 45-65. 
[13]. World Health Organization. Health education: theoretical concepts, effective strategies and core competencies, WHO Regional Office for the Eastern Mediterranean, Cairo, 2012.

[14]. Ghanbary, MK., Shamsi, M., Khorsandi, M., Farazi, A., Ranjbaran, M. and Eshrati, B. Effect of training with teaching methods designed based on health belief model on knowledge and self-efficacy in nurses on the disciplines standard precautions in hospitals, Journal of human health, 1 (2), 2015, 51-55

[15]. Chanay, MD. and Anderson, BA. Caring for the Vulnerable, perspectives in nursing theory, practice and research (4th edition, Jones \& Bartlett Publishers, USA) 2016, p. 153

[16]. Tehrani, FJ., Nikpour, S., Kazemi EA., Sanaie N. and Panahi SA. The effect of education based on health belief model on health beliefs of women with urinary tract infection, Int J Community Based Nurs Midwifery. 2(1), 2014, 2-11.

[17]. Paula, AB., Borborema-Alfaia, D., Freitas, NS., Filho, SA. and Borborema-Santos, CM. Chlamydia trachomatis infection in a sample of northern Brazilian pregnant women: prevalence and prenatal importance. The Brazilian Journal of Infectious Diseases, 17, (5), 2013, 545-550

[18]. Turay, AA., Eke, SO., Oleghe, PO. and Ozekhome, MC. The prevalence of urinary tract infections among pregnant women attending antenatal clinic at ujoelen primary health care centre, Ekpoma, Edo State, Nigeria. International Journal of Basic, Applied and Innovative Research, 3(1), 2014, 86 - 94

[19]. Goodyear, G.: Gynaecological infections, nursing in practice. 2015 Available at http://www.nursinginpractice.com/article/gynaecological-infections

[20]. Agersew, A., Feleke, M., Yitayal, s., Ketema, T., Afework, K., Belay, A. and Abebe, A. Bacterial profile and drug susceptibility pattern of urinary tract infection in pregnant women at university of Gondar Teaching hospital, Northwest Ethiopia. BMC Research Notes, 5, licensee BioMed Central Ltd. 2012, 197.

[21]. Stanton, C., Lawn, JE., Rahman, H., Wilczynska-Ketende, K. and Hill, K. Stillbirth rates: delivering estimates in 190 countries, Lancet, 367(9521), 6 May 2006, p1487-1494. Available at http://www.thelancet.com/pdfs/journals/lancet/PIIS01406736(06)68586-3.pdf

[22]. Mali, NR. and Mali, R. Effect of structured education on knowledge regarding prevention of cervical cancer among A.N.M. students, International Journal of Science and Research, 3(3), 2014, 610-616.

[23]. Khoramabadi, M., Dolatian, M., Hajian, S., Zamanian, M., Taheripanah, R., Sheikhan, Z., Mahmoodi, Z. and SeyediMoghadam, A. Effects of education based on health belief model on dietary behaviors of Iranian pregnant women, Glob $J$ Health Sci, 8(2), 2016, 230-239.

[24]. Shahnazi, H., Sabooteh, S., Sharifirad, G., Mirkarimi, K. and Hassanzadeh, A. The impact of education intervention on the Health Belief Model constructs regarding anxiety of nulliparous pregnant women, J Educ Health Promotion, 4, 27. Published online 2015 Mar 27. doi: $10.4103 / 2277-9531.154120$

[25]. Ahmed, M. Effect of intervention guidelines on self care practices of pregnant women with urinary tract infection, Life Science Journal,12(1), 2015,113-124

[26]. Jalali, M., Shamsi, M., Roozbehani, N. and Kabir, K. Investigation of health education based on theory of planned behavior on behavioral promotion of urinary infection prevention in pregnant women, World Journal of Medical Sciences 11 (4), 2014, 452-460.

[27]. Taghdisi, M.,and Sadeghi, E. The effect of health education based on health belief model on behavioral promotion of urinary infection prevention in pregnant women, Journal of Research \& Health Promot Pract; 2(1), 2012 126-136. in Persian.

[28]. Aligol, M., Nasirzadeh, M., Bakhtiari, MH. and Eslami, AA. The effects of education on promoting knowledge, beliefs and preventive behaviors on brucellosis among women: applying a health belief model, Jundishapur Journal of Health Sciences, 6(2), 2014, 243- 249.

[29]. Karimy, M., Montazeri, A., Araban, M. The effect of an educational program based on health belief model on the empowerment of rural women in prevention of brucellosis, Arak Med Univ J 14(4), 2012, 85-94.

[30]. Bakhtari Aqdam, F., Nuri Zadeh, R. and Sahebi, L. Effect of education based on Health Belief Model on Believe promotion and screening behaviours of breast cancer among women referred to Tabriz health centers, Medl J Tabriz Uni Medl Sci. 33, 2012, 2531.

[31]. Farma, KK., Jalili, Z., Zareban, I. and Pour, MS. Effect of education on preventive behaviors of breast cancer in female teachers of guidance schools of Zahedan city based on health belief model, J Educ Health Promot, v.3:77 2014.

[32]. Karimy, M., Gallali, M., Niknami, SH., Aminshokravi, F. and Tavafian, SS. The effect of health education program based on Health Belief Model on the performance of Pap smear test among women referring to health care centers in Zarandieh, Journal of Jahrom University of Medical Sciences. 10 (1), 2012, 53-59.

[33]. Sadeghi, EN., Taghdisi, MH. and Solhi, M. Effect of education based on health belief model on prevention of urinary infection in pregnant, HealthMED 6 (12), 2012, 4211-4217.

[34]. Jahanbin, I., Heydari1, N., Ghodsbin, F., and Sayadi, M. The Effect of peer-education on UTI-related preventive behavior according to HBM among first-grade high school female students in Shiraz, J Health Sci Surveillance Sys, 3(1), 2015, 20-26

[35]. Yossif, HA. \& EL Sayed, HA. Effect of self-learning package based on health belief model on cervical cancer prevention among female University students, IOSR Journal of Nursing and Health Science, 3(6), 2014, 77-88.

[36]. Pirzadeh A and Mazaheri M. The effect of education on women's practice based on the health belief model about pap smear test, International journal of preventive medicine. 3(8), 2012, 585-590.

[37]. Rahimi, SF., Zareban, I., Shahrakipoor, M., Zhianian, A., Keykhaee, Z., Hosseini, E. and karami bojd, F. Predictors of preventive behaviors of urinary tract infections based on health belief model among pregnant women in Zahedan, Caspian Journal of Health Research 1(2), 2016,9-17.

[38]. Juntasopeepun, P., Davidson, P., Suwan, N., Phianmongkhol, Y. and Srisomboon, J. Human Papillomavirus vaccination intention among young women in Thailand, Asian Pacific J Cancer Prev, 13(1), 2012, 3213-3219. 